\title{
Steroid Cell Tumor : A Rare Ovarian Tumor - Case Report
}

\author{
Falguni T. Patel, Bhoomi A. Shah*, Nisarg R. Parikh and Ratigar N. Gonsai
}

Department of Pathology, Dr. M. K. Shah Medical College and Research Centre, Chandkheda, Ahmedabad -382424, Gujarat, India

\section{ABSTRACT}

Steroid cell tumors of ovary are a rare subgroup of sex cord tumors, account less than $0.1 \%$ of all ovarian tumors and also will present at any age. Some of this tumor may be functional and secrete hormones. Nearly 56-77\% of the cases present with hypergonadism. However, there may be atypical presentations of these tumors also when they do not show any symptoms of virilization. In these cases diagnosis is usually made postoperatively on finding a tumor in ovary. A careful correlation between Clinical and surgical evaluation and microscopic analysis is necessary, as is a regular follow up. We reported a case of 45 years old female with complained of abdominal pain on \& off since two years. She had no other complains. Histopathology confirmed the diagnosis of steroid cell tumor not otherwise specified type (NOS type) with no cytological atypia.

Keywords: Steroid Cell Tumor, Ovarian Tumor

\section{Introduction}

The spectrum of ovarian neoplasms covers an extremely wide range of tumors. The common tumors are the surface epithelial cell tumors. Amongst the less common variants, lipid or steroid cell tumors comprise an important category, although they account for only $0.1 \%$ of all ovarian tumors. ${ }^{[1]}$

These tumors can produce steroids, and may give symptoms like hirsutism, hair loss, amenorrhea or oligomenorrhea. ${ }^{[2]}$ These tumors have the subtypes, based on the cells of origin, stromal Luteoma arising from ovarian stroma, Leydig cell tumor arising from Leydig cells in the hilus, and steroid cell tumor (not otherwise specified or NOS) when the lineage of tumor is unknown. ${ }^{[3]}$

This case is reported for its rarity and its unusual presentation of not having any clinical signs and symptoms typical of steroid hormone- secreting tumor.

\section{Case Report}

A 45 year old post menopausal female presented in the out patient department of Obstetrics \& Gynecology in SMS multi-speciality hospital, Chandkheda with a history of pain in lower abdomen on \& off since 2 years. She had two children and was no history of any abnormality during her pregnancy. There was no history of any contraception and exogenous hormone intake. Past medical history was otherwise unremarkable. Family history was non contributory.

Per Abdominal examination revealed soft, per vaginal examination did not yield definite findings, with a vague fullness being detected right side of uterus. Uterine size could not be made out and it is fixed.

Ultrasonography was carried out which showed a uterus with anteroverted, showed $5.4 * 4.7 \mathrm{~cm}$ subserosal fibroid in fundus and two anterior wall extramural fibroids $(2.9 * 2.3 \mathrm{~cm}$ and $1.5 * 1.1 \mathrm{~cm}$ size noted) Fallopian tubes were normal. Patient's pulse was $84 /$ minute and BP was $116 / 70 \mathrm{~mm}$ of $\mathrm{Hg}$. All other blood investigations were normal. HIV and HbsAg were negative.

A total Hysterectomy with bilateral salpingo-oophorectomy was done and the specimen was received in pathology department for histopathological examination.

Gross examination : An already cut open gross specimen of uterus and cervix with both adnexa was received totally measuring $11 * 8 * 4.5 \mathrm{~cm}$ in size. Uterus and cervix measuring $11 * 4 * 4.5 \mathrm{~cm}$. On cut section three fibroids were noted, one subserosal fibroid measuring $1.5^{*} 1.0 \mathrm{~cm}$ and two intramural fibroids out of which largest fibroid measuring $2.5 * 2.5 \mathrm{~cm}$, cervix exhibited the nabothian cyst. Right sided ovary measuring $5 * 5 * 3 \mathrm{~cm}$ in size, external surface revealed grayish white lobulation, on cut section yellowish and solid area which was replacing almost whole of the ovary (Fig 1 a \& b) and Fallopian tube measuring $2 \mathrm{~cm}$ in length. Left sided ovary measuring $2.5^{*} 1.5^{*} 1 \mathrm{~cm}$ and cut section shows solid and normal architecture and fallopian tube measuring $3.5 \mathrm{~cm}$ in length.

Light microscopy : Sections from right ovarian tumor showed well circumscribed tumor. The cells are arranged 
diffusely, medium to large size, round to polygonal in shape with centrally placed nuclei and clear vacuolated moderate amount cytoplasm containing lipids, which are similar to adrenocortical cells. ${ }^{[4]}$ They have distinct cell membranes.(Fig 2 a \& b) There was no atypia, mitotic figures or necrosis noted in the tumor. Stroma was scanty and minor fibromatous component and loose vascular channels randomly distributed. Histological features was consistent with steroid cell tumor NOS type. The other side ovary and tube was unremarkable. The cervix showed hyperplastic squamous epithelium and features of chronic cervicitis with nabothian cyst while the endomyometrium showed cystic hyperplasia and features of leiomyoma.

\section{Discussion}

This article describes a rare entity of ovarian tumor in 45 year old menopausal women without any androgenic symptoms. Patient had only complain of lower abdominal pain on \& off since 2 years. Patient underwent for Total abdominal hysterectomy with bilateral salpingooophorectomy. USG showed a fibroid in uterus and ovarian mass at right side.

Steroid cell of ovary was first described by Scully in 1987. These tumors accounts for less than $0.1 \%$ of all ovarian neoplasms. ${ }^{[4]}$ There are three subtypes of steroid cell tumors according to the cell of origin: a) stromal luteomas arising from ovarian stroma $(20 \%)$ which shows presence

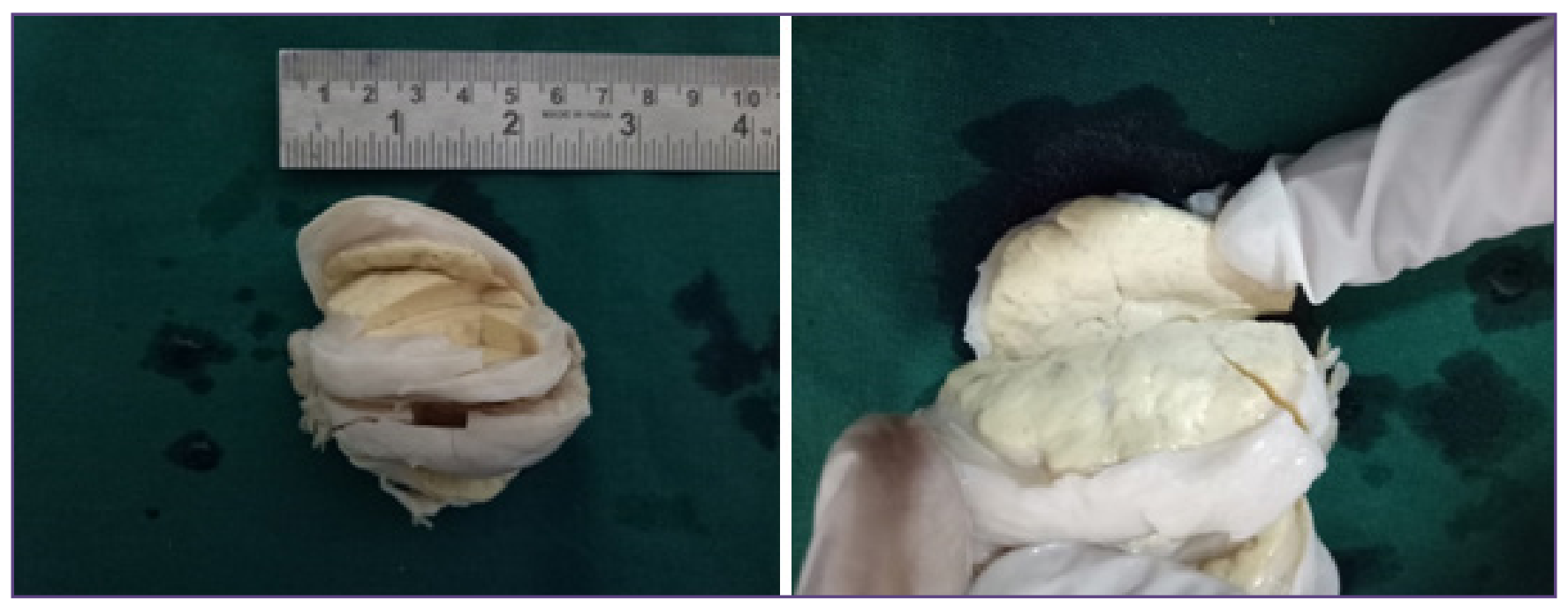

Fig. 1: (a)\&(b).(a) Gross appearance of steroid cell tumour of right ovary shows greyish white lobulated outersurface. (b) Cut section shows predominantly solid, yellowish area measuring $5 \times 5 \times 3 \mathrm{~cm}$ in size.

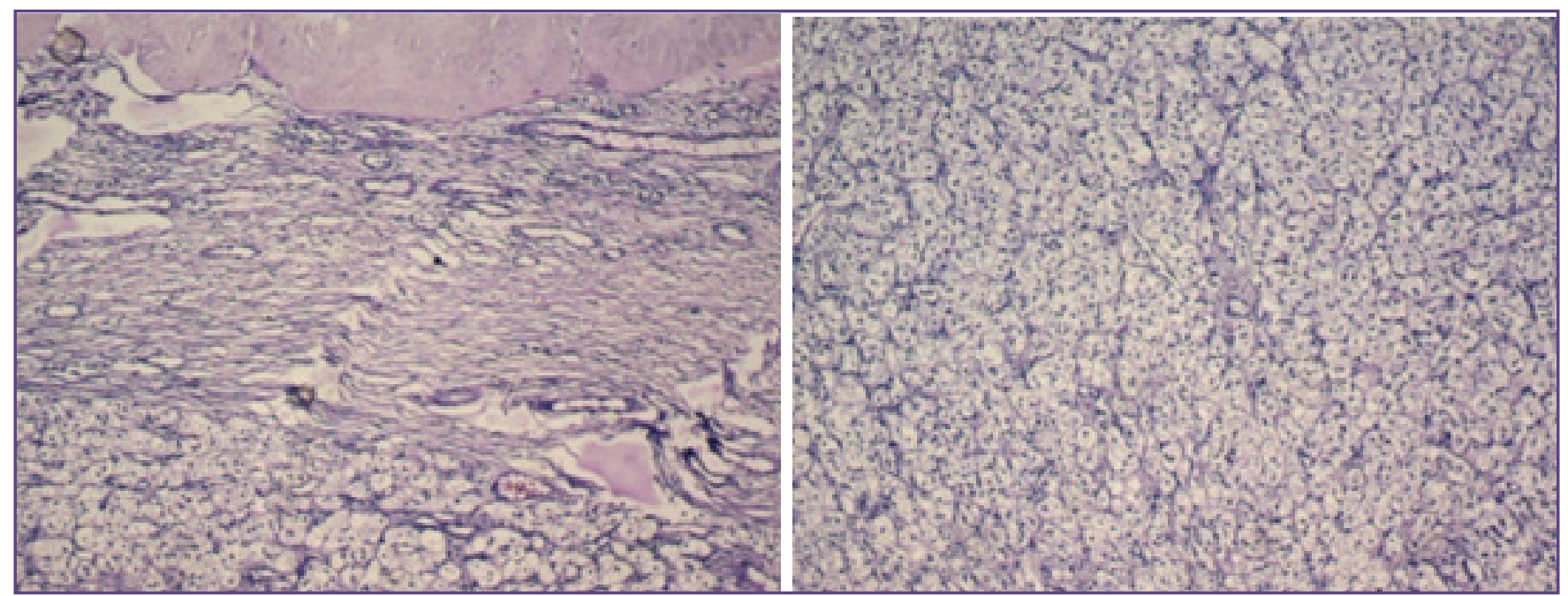

Fig. 1: (a)\&(b).(a) Gross appearance of steroid cell tumour of right ovary shows greyish white lobulated outersurface. (b) Cut section shows predominantly solid, yellowish area measuring $5 \times 5 \times 3 \mathrm{~cm}$ in size. 
of degerative pseudovascular spaces containing red blood cell $^{[5]}$ and b)Leydig cell tumors arising from Leydig cells $(20 \%)$ and it shows cytoplasmic reinke crystals and Leydig cell hyperplasia. ${ }^{[6]}$ c) steroid cell tumor not other wise specified when the lineage of tumor is unknown $(60 \%)$. [7] Our patient had NOS type steroid cell tumor. Grossly these tumors are commonly solid, however a combination of solid and cystic form or predominantly cystic form may also be seen. The color of cut surface may range from yellow to orange to red or brown depending upon the lipid content. Area of hemorrhage and necrosis may also be seen. ${ }^{[8]}$ The tumor in our case was completely solid with no cystic area. The cut surface was typically yellowish and lobulated. Microscopically there was no feature of like stromal luteoma and leydig cell tumor. It composed of granular eosinophilic and vacuolated cytoplasm without any type of nuclear atypia.

Steroid cell tumors are generally unilateral and benign, malignancy is generally associated with identification of the histopatholoic findings: two or more mitotic figures per 10 high-power fields $92 \%$ malignant, necrosis $86 \%$ malignant, size of $7 \mathrm{~cm}$ or larger $78 \%$ malignant, hemorrhage $77 \%$ malignant, and grade $2 / 3$ nuclear atypia $64 \%$ malignant. $^{[4]}$ For our patient, the pathology result revealed $5 \mathrm{~cm}$ size of unilateral mass, without atypia, necrosis, and mitosis.

A clinico-pathological correlation is very important in these tumors as the benign looking tumors on histomorphology can behave in a clinical malignant manner. ${ }^{[9]}$ Inhibin is useful in differentiating this tumor from other non sex cord stromal tumor. ${ }^{[10]}$ Nearly $56-77 \%$ of the cases present with hypergonadism. ${ }^{[8]}$ Our patient presented without any symptoms related to steroid hormone secreting tumor.

\section{Conclusion}

Ovarian steroid cell tumors, grouped under sex-cord stromal tumors, account for less than $0.1 \%$ of all ovarian tumors. They are usually benign, unilateral and are characterized by a steroid cell proliferation. Generally presented with a history of androgenic symptoms. Our case is unique because it is presented without any androgenic symptoms which is very rare presentation. The primary treatment is surgical removal, but close follow up is necessary for any kind of metastasis because pathologically benign tumors can behave in a clinically malignant fashion.

\section{Reference}

1. Young RH, Clement PB, Scully RE. Sex-cord, stromal, steroid cell and germ cell tumours of the ovary. In: Mills S-E, Carter D, Greenson JK, Oberman H-A, Reuter V \& Stoler M-H. Sternberg's Diagnostic Surgical Pathology 4th ed. Philadelphia: Lippincott Williams \& Wilkins; 2004, 2579-2615.

2. Powell JL, Dulaney DP, Shiro BC. Androgen-secreting steroid cell tumor of the ovary. Southern Medical Journal, 2000; 93(7-12):1201-4.

3. Young RH, Clement PB, Scully RE. Sex cord stromal, steroid cell and germ cell tumours of ovary. In: Mills SE, Carter D, Greenson JK, Reuter VE, Stoler MH, editors. Sternberg's Diagnostic Surgical Pathology Volume 2. 5th ed. Philadelphia: Pa, USA: Lippincott Williams and Wilkins; 2009: 2592-2595.

4. Hayes MC, Scully RE. Ovarian steroid cell tumours (not otherwise specified): a clinicopathological analysis of 63 cases. Am J Surg Pathol 1987;11:835-45.

5. Scully RE. Stromal luteoma of the ovary. A distinctive type of lipoid cell tumour. Cancer. 1964;17:769-78.

6. Paraskevas M, Scully RE. Hiluscell tumour of the ovary. A clinic-pathological analysis of 12 Reinke crystal-positive and nine crystal- negative cases. Int J Gynecol Pathol. 1989;8(4):299-310.

7. Outwater EK, Wagner BJ, Mannion C, McLarney JK, Kim B: Sex cord-stromal and steroid cell tumors of the ovary. Radiographic 1998, 18:1523-46.

8. Liu AX, Sunj, Song WQ: Steroid cell tumours, not otherwise specified, in an accessory ovary: a case report and literature review. Gynecol Oncol 2005, 97:260-2.

9. Mehdi G Ansari HA, Sherwani RK, Rahman K, Akhtar N. Ovarian Steroid Cell Tumour: Correlation of Histopathology with Clinico-pathologic Features. Pathology Research International.2011;5 pages.

10. Rabban JT, Zaloudek CJ. A practical approach to immunehistochemical diagnosis of ovarian germ cell tumours and sex cord-stromal tumours. Histopathology. 2013;62:71-88.

*Corresponding author:

Dr. Bhoomi A. Shah, 1, Roopam society, Near vijay cross road, Navrangpura, Ahmedabad, 380009.

Phone: +919429840033

Email: bhoomigandhi61@gmail.com

Financial or other Competing Interests: None. 